\title{
Philosophy of Science in Japan $1971-1975$
}

This report is a continuation of professor Hiroshi Nagai's 'Philosophy of Science in Japan 1966-1970' (The Annals of the Japan Associstion for Philosophy of Science, Vol. 4, No. 1, 1971). The study of the philosophy of science has been very active over the past years and the results of many research works were published in the last five years in Japan. We refer to its main trends in this paper.

One of the main currents of the philosophy of science is analytic philosophy. Of course, analytic philosophy is not the same as the philosophy of science but philosophical analysis has been a prevalent method used to solve the problems of the philosophy of science. Natsuhiko Yoshida, a representative analytic philosopher, attaches much importance to the role of language in our cognition of reality in his Language and Reality (Shinyosha, Tokyo, 1971), which is a collection of his theses, dealing with many subjects. The formalism of foundations of mathematics and set theory highly influences his philosophical theory.

Thus, the philsophical investigation of language is one of the central themes of the philosophy of science. Philosophy of Language (ed. by Hyakudai Sakamoto, Gakubunsha, Tokyo, 1972) surveys systematically the main problems of language which are manifold from the point of view of philosophy and of the philosophy of science. This is a very excellent introductory book to the philosophy of language.

Wataru Kuroda's Experience and Language (Tokyo Daigaku Shuppankai, Tokyo, 1975), a collection of his theses, is an illuminative book. He rejects the view "the meaning of a proposition is the method of its verification", because it sets the proposition on the one side and the fact on the other. The relation between language and experience is not external but internal, and understanding meaning reveals this internal connection. When we grasp the meaning of a word, the meaning of the experience is understood simultaneously.

On the other hand, Shozo Ohmori, one of the representatives of the philosophy of science, issued a very interesting thesis 'World-Soul Theory', which was included in World and Knowledge, Lectures on Philosoohy, Vol. 2 (ed. by S. Ohmori, Tokyo Daigaku Shuppankai, Tokyo, 1973). World-soul means the spiritual power of the word to call forth a fact. Generally a distinction has been drawn between the object (a thing or a fact) and its idea (a perceptual representation or an image). This idea is the so-called meaning of the word. A dualism between the object and the idea is not good. The word calls forth the object immediately, and not that the image of the object is evoked through the meaning of the word. He hold monism in this manner. Ohmori's thesis has influenced many philosophers and others, and active discussions concerning this thesis have been caried on. $\mathrm{He}$ 
also published Language, Perception and World (Iwanami Shoten, Tokyo, 1971), which includes other interesting theses of his.

World and Knowledge includes some other interesting articles concerning the philosophy of science, that is, Takashi Fujimoto's 'The Privacy of Consciousness and the Publicity of Language', Yoichiro Murakami's 'Fact, Law, and Theory', N. Yoshida's 'Problems of Multivocal', Hiroshi Kurosaki's 'Theory and Experience', and H. Sakamoto's 'Causation, Determination and Freedom' and other. All these papers are leading works which indicate the high level of the philosophy of science in Japan. Y. Murakami also published Beyond Modern Science (Nihonkeizai Shinbunsha, Tokyo, 1974), in which he discusses the interplay of theory and experience as the structual elements in the development of modern science through a totally new approach.

Jun'ichi Aomi, a representative philosopher of law, published Restoration of Rationalism (Bokutakusha, Tokyo, 1973), a collection of his theses, in which he develops many themes concerned with the philosophy of the social sciences. Referring to the thoughts of Bertrand Russell, Ernst Topitsch, Karl Popper and others, he intends to defend rationalism or scientific outlook in this work.

Logic, along with language, is also one of the main problems of the philosophy of science. Logic can be approached from two angles i.e. philosophy and mathematics. Shigeo Nagai, a representative analytic philosopher, seeks to elucidate the meaning of modern logic that is considered to be at the basis of all sciences in his Science and Logic (Kawade Shobo Shinsha, Tokyo, 1971). He succeeds in making clear what logic is concretely, explaining the object of logic, and syntax, semantics and pragmatics as methods of logic. S. Nagai also published What is Analytic Philosophy? (Kinokuniya Shoten, Tokyo, 1973) and The Logic of Philosophical Knowledge (Waseda Daigaku Shuppanbu, Tokyo, 1974).

In the field of philosophical logic Hiroshi Endo investigates the logical meaning of existence in his Logic of Existence (Waseda Daigaku Shuppanbu, Tokyo, 1974). He approaches this problem by the method of formal semantics, and develops interesting views. Yoshimi Fujikawa issued Logic of the Systematization of Language (Waseda Daigaku Shuppanbu, 1975), in which he intends to construct a logical method or logical model of the unity of science. He also published Methods of Mathematical Logic (Risosha, Tokyo, 1974). Hidekichi Nakamura treats of paradoxes interestingly in their totality from the point of view of logical analysis in his Paradoxes (Chuokoronsha, Tokyo, 1972).

Shoji Maehara and Gaishi Takeuchi are representative mathematicians in the field of foundations of mathematics in Japan. S. Maehara's Mathematical Logic (Baifukan, Tokyo, 1973) presents an excellent treatment chiefly of Gentzen's system of logic as well as other topics. G. Takeuchi, presently a professor of the University of Illinois. U.S.A., treats the tenth problem of Hilbert and the word 
problem in group in his Mathematical Logic, (Baifukan, Tokyo, 1973).

Surpassing analytic philosophy, Nobushige Sawada, one of the precursors of analytic philosophy, attempts to establish his original thought in the field of theory of knowledge in his Landscape of Cognition (Iwanami Shoten, Tokyo, 1975). He makes much of the role of sense-perception in our cognition. However, this senseperception is not a patch as empircists and sensationalists think so in general, but concrete and total. He calls such sense-perception 'perceptual landscape' and tries to solve the problems which modern European scientific culture faces.

Hiroshi Nagai, one of the representatives of the philosophy of science, from the ontological point of view, firmly sserts that logico-linguistic analysis is a sound theory within the scope of the explanation of ready-made scientific theories, but science should be regarded as a research-science of unknown truth. This time he argues on the theory of life from the metabiological point of view in his outstanding book Philosophical Foundations of the Theory of Life (Iwanami Shoten, Tokyo, 1973). Metabiology is a philosophical invstigations related to both biology and philosophy in seeking the nature of life ontologically, because this theory of life is a premise of biological study and treats a fundamental problem of philosophy at the same time. He elucidates life and human being in this way. His theory influenced biologists and philosophers, and was appraised highly. H. Nagai established his system of philosophy of science with this book and two other formerly published books, Ontological Foundations of Mathematics and The Study of Modern Natural Philosophy.

In the field of methodology, Takahiko Yamanouchi, a famous physicist, compiled Method of Modern Science (Nihon Hoso Shuppan Kyokai, Tokyo, 1971), which aims at the establishment of the methodology of the sciences according to the findings of modern sciences. This book includes Y. Murakami's 'Method of Physics and Mathematics', Koji Kihara's 'Method of Biology', Taro Indo's 'Method of Psychology', Ryuichi Nagao and Osamu Hamai's 'Method of Soical Science' and Hikaru Furuta's 'Method of Science and Method of Philosophy'.

Ken'ichi Shirakami, a biologist, stated a remarkable methodology of biology on the basis of the study of his specialty, cytro-embryology, in his Biology and Method (Kawade Shobo, Tokyo, 1972). In this work mechanism, heuristics, analogy etc. are discussed concretely and interestingly in connection with the methodology of biology.

Aritsune Tsuzuki and Ben Yagi, both psychologists, compiled Research Methods of Psychology 17 Vols. (Tokyo Daigaku Shuppankai, Tokyo, 1972-1975). This series deals with all method of psychology concretely and can be regarded as an encyclopedia of methods of psychology.

The nature of science also can be clarified from its historical aspects. Akio Ogiwara's Origins of Modern Science (Sogensha, Tokyo, 1975) deals with the 
problems of scientific discoveries and inventions made mainly in the seventeenth century. He stresses that metaphysics is at the basis of such discoveries and inventions, and elucidates the mutual relation between metaphysics and science. Toru Hiroshige, Shuntaro Ito and Y. Murakami are representatives of the history of science. They published a notable introductory book on the nature of science in Science in the History of Thought (Bokutakusha, Tokyo, 1975) based on historical research.

From the point of view of dialectical materialism, Chikatsugu Iwasaki, a philosopher and Shohei Miyahara, a physicist, published a comprehensive book Modern Natural Science and Materialistic Dialectic (Otsuki Shoten, Tokyo, 1972). Basing themsevles on the developments of modern science, they intend to comprehend the total field of science through epistemological studies. Further, Akima Minoru's two books, Modern Science and Materialism (Shinnihon Shuppansha, Tokyo, 1971) and The World of the Philosophy of Science (Otsuki Shoten, Tokyo, 1974) are written from the same point of view.

Shuro Honda, a philosopher, criticized Hegelian mathematics and natural philosophy with reference to modern natural science in his Hegelian Dialectic and Science (Risosha, Tokyo, 1971). He does not treat 'of materialistic dialectic but of the dialectic of Nature in the field of natural philosophy.

Many interesting themes have been under discussion in the area of the philosophy of science over the past years. The notion of 'Time' has been one main theme of these discussions. Satoru Watanabe, a physicist and presently a professor of the University of Hawaii U.S.A., published History of Time (Tokyo Tosho, Tokyo, 1973). The intention of this book is to retrace the birth and growth of time as a physical concept. Time (Kawade Shobo Shinsha, Tokyo, 1974) is another book of his. Koji Fushimi and Mutsuo Yanase are physicists. They compiled What is Time? (Chuokoronsha, Tokyo, 1974), to which the leading scientists contributed.

Takeo Sugihara, a philosopher and logician, deals with the logical structure of time in his interesting book Logic of Time (Waseda Daigalku Shuppanbu, Tokyo, 1974). He argues about many aspects of time philosophically and throws light on its structure through symbolic logic.

Chikio Hayashi, a mathematician and president of the Japan Association for the Philosophy of Science, headed many investigations concerned with the philosophy of science. One of these investigations is 'The Study of Method and Classification of Sciences from the point of view of Philosophy of Science', to which many scientists, mathematicians and philosophers contributed and some results were published in Kagaku Kisoron Kenkyu Vol. 12, No. 1 (1974), a publication of this association.

Finally, I would like to list the themes of the special issues of Kagaku Kisoron Kenkyu in these five years. They are 'Some Topics on Information Sciences', 'On 
Carnap and Russell', 'Wishes to Mathematics', 'Creativity in Science', 'Modern Biology', 'Some Problems in Measurement of Psychology', 'Problems of Language', 'Methodology of Science' and 'Foundations of Science'. These themes illustrate some of the major trends of interest in the field of the philosophy of science in Japan.

(Heiji Teranaka) 